\title{
MOŽNOSTI UPORABE GIS V KRAJINSKEM PLANIRANJU
}

\author{
Ivan Marušic
}

Izvleček

UDK 712:91:681.3

Uporaba GIS programov $v$ krajinskem planiranju ima dolgo tradicijo. Na Slovenskem prvi začetki segajo $v$ zgodnja 70 -ta leta $v$ okviru presoj vplivov na okolje in različnih vrednotenj in analiz krajinskega prostora. Iz tujine pridobljeni programi so se dopolnjevali in prilagajali domačim razmeram in problemom. $V$ referatu so prikazane posamezne naloge, $k i$ so se izvajale s pomočjo doma izpoponjenih in kasneje tudi $v$ celoti doma razvitih programov. Gre za različne oblike vključevanja okoljevarstvenih zahtev $v$ prostorsko načrtovanje, pa tudi za bolj izpopolnjene postopke načrtovalne sinteze. Vsa različna opravila se nanašajo na pretvorbo osnounih iz realnega prostora zajetih podatkov. Takim pretvorbam služijo modeli, ki so tipološko klasificirani kot:

(1) prikazovalni, (2) analitično raziskovalni, (3) simulacijski, (4) evaluacijski, (5) sintezni in (6) odločitveni modeli.

Abstract

UDC 712:91:681.3

\section{THE POSSIBILITIES OF APPLICATION OF GIS IN LANDSCAPE PLANNING}

The application of GIS technology in Slovenian landscape planning practice goes back to the beginning of the 70-ties when early types of GIS programs have been introduced to the country. They have been used within the environmental impact studies and land use planning projects and gradually adapted to the particularities of Slovenian planning practice. The paper represents some types of data processing that have been applied in various planning projects. The type of data processing within the GIS technology is defined by a model that should be based on generalized expert knowledge. There are several types of models for data processing within the landscape planning process: (1) representation models, (2) models for analysis or research models, (3) simulation models, (4) evaluation models, (5) models for synthesis, and (5) decision models.

\section{UVOD}

Začetke in zasnove sodobnih GIS aplikacij je gotovo potrebno iskati $\mathrm{v}$ zgodnjih programskih rešitvah prenosa prostora $\mathbf{v}$ digitalno in računalniku

Dr. Ivan Marušič, Katedra za krajinsko arhitekturo Oddelek za agronomijo Biotehniška fakulteta Jamnikarjeva 101, 61000 Ljubljana 
dosegljivo obliko. Tovrstne aplikacije so bile tudi pri nas znane že na začetku 70-tih letih kot program SYMAP in njegove različice (Kristan, 1972). Tedaj so se $\mathbf{s}$ to računalniško aplikacijo veliko ukvarjali $v$ okviru Inštituta Geodetskega zavoda Slovenije. Današnji digitalni model reliefa Slovenije je bil zasnovan že takrat in prav $v$ okviru takratnih prizadevanj za digitalizacijo prostorskih podatkov (Banovec, 1972). Prizadevanja so bila širša in naravnana na izgradnjo splošnega prostorskega informacijskega sistema Slovenije. Tudi današnji sistemi prostorskih informacij, ki jih v Sloveniji imamo poleg digitalnega modela reliefa, so rezultat takratnih pionirskih prizadevanj.

\section{UPORABA GIS V KRAJINSKEM PLANIRANJU}

V letih 1973-1974 smo v okviru Katedre za krajinsko arhitekturo pri Biotehniški fakulteti $v$ Ljubljani uvedli $v$ uporabo programski paket GRID, ki so ga razvijali $v$ okviru Laboratorija za računalniško grafiko pri Univerzi Harvard v ZDA. Program je bil kasneje razširjen in preimenovan $v$ GRIDMAP (Marušič, 1980, 1981) in tudi ta verzija je bila prenesena na slovenska tla. Ti programi niso bili le kartografsko orodje. Imeli so vrsto rešitev, ki so bile namenjene njihovi uporabi pri prostorskem planiranju. Pravzaprav je bila pri njihovem razvoju posebej poudarjena uporaba $v$ krajinskem načrtovanju. Programi so tako uresničevali vrsto načrtovalnih zamisli, tudi takih, ki so se zasnovali ob uvajanju presoj vplivov na okolje. $\mathrm{V}$ tem času so te bile novost $\mathrm{v}$ ameriški načrtovalni praksi in akademske institucije so si prizadevale razviti zanje ustrezne metode.

Prva naloga, ki smo jo tedaj izvedli $z$ omenjenim programskim paketom, je bila Analiza in valorizacija načrtovanih tras avto ceste na območju Ljubljana-Kranj (1974). V resnici je to bila ena prvih pravih presoj vplivov na okolje na Slovenskem. V prilogi 1 predstavljena shema celotnega postopka odkriva dokaj kompleksno zgradbo, katere osrednji del je skupina prostorsko valorizacijskih modelov. Ti so ločenih po vsebini na dve temeljni skupini:

- na modele privlačnosti, katerih namen je razkriti kje in koliko je prostor ustrezen za kar najbolj ceneno in prometno ugodno speljavo ceste in

- na modele ranljivosti, katerih namen je pokazati, kje in kako intenzivno lahko taka dejavnost, kot je cesta in promet na njej, vpliva na posamezne sestavine $\mathrm{v}$ okolju

$\mathrm{V}$ nalogi je bil poudarek na drugi skupini modelov. Njen namen je, namreč, bil preveriti, katera od predlaganih različic avto ceste je najbolj sprejemljiva glede na zahteve varstva okolja. Tako preverjanje pa je mogoče sorazmerno enostavno izpeljati s tem, da posamezne kartografske prikaze vplivov avto ceste na okolje prekrijemo $z$ zemljevidom variantnih tras in pri tem obseg vplivov lahko tudi numerično izrazimo. 
Z raziskovalno nalogo Metodologija krajinskega planiranja na primeru Goriških Brd (1975) smo k programskemu paketu že dodali lastne rešitve. Paket smo namreč prilagajali naši praksi $\mathrm{v}$ prostorskem načrtovanju. Tedaj je bila zelo aktualna razprava o potrebi po varovanju kmetijskih zemljišč. Ob tem so se odpirala vprašanja, kako kmetijska zemljišča vrednotiti. S to nalogo smo uvedli pojem ustreznost zemjišča (priloga 2). Ta je rezultat sinteznega modela, ki povezuje samo vrednost zemljišča za kmetijsko pridelavo, ali katero od njenih oblik, na primer sadjarstvo in okoljevarstvenih opozoril, kot je na primer, kje lahko kmetijska pridelava naredi okolju škodo. Vrednost kmetijskega zemljišča, torej, ne opredeljujejo samo tehnologija, stroški pridelave ter kakovost in cena pridelanega proizvoda, temveč tudi zahteve za ohranjaje okoljskih in ekoloških kakovosti krajine. Poudarjanje okoljskih vprašanj $\mathrm{v}$ zvezi $\mathrm{s}$ kmetijsko pridelavo je bilo tedaj še močno preuranjeno in morali smo doživeti obsežne hidromelioracijske posege, preden smo se ovedli upravičenosti okoljevarstvenih opozoril tudi v kmetijstvu. Druga posebnost, ki smo jo tedaj ponudili snovalcem postopkov kategorizacije kmetijskih zemljišč, je bila ločeno vrednotenje zemljišč za posamezne oblike kmetijske pridelave, kot so sadjarstvo, vinogradništvo, njivska, travniška pridelava itd. Seveda je tako členjeno vrednotenje prostora, ki hkrati upošteva tudi številne možne vplive kmetijske dejavnosti na okolje, predvsem tehnično zahtevno opravilo in računalnik je pri tem skoroda neogiben. Razširjenost računalnikov pa je tedaj bila še zelo skromna. Morda tudi zato predlagani postopki tedaj niso naleteli na ugoden odziv kmetijskih krogih.

V okviru mednarodnega projekta Jadran III - Varstvo okolja v Jadranski regiji Jugoslavije (1976) smo storili še korak naprej in dodali modelu ustreznosti še zamisel takoimenovanega strateškega načrta varovanja naravnih virov (priloga 3). Načrt je računalnik samodejno pripravil s sestavljanjem območij največje ustreznosti za posamezne primarne dejavnosti. To pa so bile: kmetijstvo s posameznimi vejami, na primer zelenjadarstvo, sadjarstvo, vinogradništvo, marikulure, pridobivanje soli, vodno gospodarstvo, gozdarstvo, rekreacija, turizem in naravni rezervati. Načrt je bil zamišljen kot osnova za oceno sprejemljivosti razvojnih, predvsem urbanističnih načrtov in se je opiral na zahteve po varovanju naravnih virov kot ene od skupin okoljevarstvenih zahtev. Urbanistični načrt je bi zato preverjan po dveh poteh:

- ali je konflikten $z$ načrtom rabe naravnih virov in

- koliko vplivov sproža na druge sestavine okolja.

Kaže poudariti, da so bili valorizacijski modeli $\mathrm{v}$ vseh omenjenih nalogah sestavljeni na osnovi ekspertnih znanj. Ta so bila pridoblejena bodisi na sestankih ali $\mathrm{v}$ intervijujih $\mathrm{z}$ ustreznimi strokovnjaki, ki smo jih predhodno seznanili s cilji naloge, s problemom naloge. Merila so bila opredeljena $\mathrm{v}$ skladu $\mathrm{z}$ razpoložljivimi podatki $\mathrm{v}$ podatkovni banki. Tu nimamo prostora za razlago zgradbe posameznih modelov. Za predstavitev vsakega od njih bi bil potreben poseben referat. Njihova splošna značilnost je bila, da 
so združevali $v$ eno dve opravili, ki ju je resda večinoma težko ločiti, ki pa ju vendarle moramo razlikovati:

- poustvarjanje potencialne spremembe prostora; ta se da prikazati $v$ eni od običajnih merskih enot, kot so prostorninske, dolžinske ali časovne enote, enote koncentracije, frekvenca dogodkov, verjetnost zanje in podobne, in je objektiven del analize ter

- pripisovanje pomena potencialni spremembi, ki je $\mathbf{v}$ primeru ranljivosti prostora numerično ali nominalno izražena kot stopnja sprejemljivosti ali nesprejemljivosti spremembe in je po naravi subjketivna ocena.

Ker je običajno količina spremembe $v$ neposredni zvezi $z$ oceno njene sprejemljivosti, je združevanje teh dveh opravil dokaj smiselno in logično, čeprav po drugi strani lahko zamegli subjektivno naravo ocene sprejemljivosti spremembe $\mathrm{v}$ okolju.

Z ustanovitvijo Univerzitetnega računaskega centra in s prehodom na Digitalov računalnik (DEC-10) smo po naročilu takratne Iskre-Delta razvili lasten programski paket (Marušič, 1985). Ob tem smo izrabili vse predhodne izkušnje $z$ uporabo harvardskih programov in lastnih dopolnjevanj. Ostali smo tudi $v$ okvirih rastrske digitalizacije prostora. V paketu je bilo mnogo originalnih rešitev. Predvsem je veliko širši razpon načrtovalnih opravil imel ustrezne programske rešitve, na primer različnim merilom prilagojena kartografija, računanje različnih tipov izvedenih podatkov, bogata izraba digitalnega modela reliefa, iz katerega je bilo mogoče računati strmine pobočij, njihovo izpostavljenost stranem neba, osončenost, dolžino, pa tudi posamezne geomorfološke pojave, kot so grebeni, doline, nenazadnje tudi vidni stik ned točkami v prostoru. Program je omogočal uporabiti različne oblike vrednotenja prostora, na primer postopek $\mathrm{z}$ uporabo izločilnih dejavnikov, linearni model, logična pravila ocenjevanja, pa še vrednotenja različic načrtov, statistične analize sopojavljanja in predvsem opravila načrtovalne sinteze, kot so samodejno sestavljanje načrta namebnosti prostora in samodejno lociranje dejavnosti.

Kaže poudariti, da so bile $\mathrm{v}$ paketu vgrajene pretvorbe podatkov, predvsem izračunavanja izvedenih podatkov, naravnane $\mathrm{v}$ neposredno uporabo $\mathrm{v}$ valorizacijskih modelih. Kartografsko prikazovanje ni bil namen pretvorbe podatkov, čeprav je, seveda, bilo možno. Tako računanje vidnega stika ni imelo namen prikazati zemljevid območij, ki so bodisi vidna ali skrita $z$ določene točke ali točk $v$ prostoru, temevč pripraviti podatek, ki bi ga lahko neposredno uporabili $\mathrm{v}$ valorizacijskem modelu. Zaporedje izračuna območij vidnega stika oziroma vidne sence je dalo rezultat $v$ obliki podatka o tem, kako pogosto je neko zemljišče videti pri vožnji vzdolž neke ceste. ' Končni rezultat takega izračuna je podatek o tem, kako pogostoma posamezna zemljišča $v$ dolini Krke vidimo s ceste. Pogostejša vidna izpostavljenost zemljišča pomeni za določene namembnosti njegovo večjo ustreznost, za druge pa lahko prav obratno. Predpostavimo, da iščemo najustreznejše mesto za počitniške hišice $\mathrm{v}$ prostoru. 
Tako mesto naj bi omogočalo kar moči velik razgled po prostoru. Smiselno je namreč, da kolikor le mogoče ustrežemo bodočim lastnikom teh hišic in lep razgled je $v$ tem primeru zelo iskana dobrina. Toda to je le en vidik ustreznosti lokacije. Načrtovalno izhodišče, ki je bilo preverjeno s pomočjo javnomnenjske ankete med lokalnim prebivalstvom, je bilo tudi, da je potrebno počitniške hišice kolikor mogoče skriti pred pogledi $\mathrm{z}$ najbolj obljudenih mest $v$ prostoru. To pa so vasi, ceste, območja za rekreacijo in podbna. Območja ustreznosti je mogoče iskati tam, kjer so zemljišča po obeh merilih hkrati najugodnejša.

Možnost samodejnega izvajanja sinteznih načrtovalnih opravil je zelo pomebna predvsem zaradi dejstva, da se ob tem opravilu začenjajo oblikovati različice rešitev. Računalnik je zelo priročno za iskanje rešitev, kar je sicer zamudno in ob intuitivnem delu zaradi možnih načrtovalčevih preferenc tudi subjektivno opravilo. Računalnik dosledno upošteva postavljena pravila in zato $\mathrm{z}$ njim lahko preiščemo celotno polje možnih rešitev. Primer iskanja območja za lokalno smučišče predstavlja popolnoma samodejen postopek izbire lokacije iz predhodno izračunane ustreznosti prostora. Računalnik se ravna po pravilih glede izbire ravni ustreznosti, velikosti in oblike območja smučišča.

Programski paket je bil uporabljan v rednem pedagoškem delu pri študiju krajinske arhitekture, na nekaterih podiplomskih programih na Biotehniški fakulktetị, v okviru IPŠPUP-a na Fakulteti za geodezijo, gradbeništvo in arhitekturo ter na podpilomskem študiju krajinske arhitekture v Zagrebu, toda tudi pri številnih povsem konkretnih načrtovalnih nalogah, pri presojah vplivov na okolje, na primer za avto cestne različice, pri pripravi krajinskih zasnov, pa tudi pri analizah namenjenih urbanističnemu načrtovanju, načrtovanju zelenih površin in podobno. Nekatere njegove dele so uporabljali na Zavodu za urbanizem v Velenju, najprej v okviru raziskovalne naloge, kasneje pa tudi ob rednih načrtovalnih nalogah. Najpomembnejša hiba programskega paketa je bila njegova vezanost na velik računalnik. Takratne načrte, da ga prilagodi uporabi na njenih osebnih računalnikih, Iskra-Delta ni uresničila, prav tako tega nismo storili na naši ustanovi. Nekater njegove funkcije so $\mathrm{v}$ zadnjih letih prenesli na Zavodu za urbanizem $\mathrm{v}$ Mariboru $\mathrm{v}$ okolje osebnega računalnika in jih tudi že praktično uporabili pri načrtovanju lokacij odlagališč odpadkov.

\section{SKLEP}

Različne možne oblike uporabe GIS $\mathrm{v}$ načrtovanju je mogoče pojasniti $z$ načinom predelave prostorskega podatka, to je $\mathrm{z}$ modeli njihove različne pretvorbe. Pri tem sta pomembni dve obliki informacij ali znanja: 
- prostorski podatki ter

- znanja, ki jih je mogoče označiti kot strokovno vednost, in ki $\mathrm{v}$ resnici predstavlja posplošeno znanje o prostoru, teorije in zakonitosti, $v$ načrtovanju pa tudi vednost o družbenih preferencah, interesih. ${ }^{2}$

Modele za pretvorbo podatkov je mogoče klasificirati v naslednje skupine:

- prikazovalni modeli

- analitično raziskovalni modeli

- simulacijski modeli

- valorizacijski modeli

- sintezni in

- odločitveni.

Pokazana tipologija modelov sledi strukturi načrtovalnih opravil $v$ splošnem vzorcu načrtovalnega postopka. ${ }^{3}$ Večinoma smo omenjene modele že spoznali $\mathrm{v}$ predstavljenih primerih.

Prikazovalni modeli so različne oblike preslikave stvarnosti v digitalno obliko in, kot že zapisano, prav ti modeli v veliki meri zaposlujejo programerje in uporabnike GIS programskih paketov. Med analitično raziskovalne bi lahko uvrstili vse modele, ki jih uporabljamo za ugotavljanje novih značilnosti prostora in iskanje splošnejših znanj o njem. Analiza vidnega stika med točkami v prostoru je že primer takega raziskovalnega modela. Toda lahko bi predstavili tudi bolj kompleksne raziskovalne model. Pomembno je, da so prav ti modeli vir novega stvarnega znanja o prostoru in njegovih zakonitostih in pravzaprav tudi temeljna opora pri gradnji samo učečih se načrtovalnih sistemov. Simulacijski modeli so oblika raziskovalnih modelov, pri katerih poskušamo pogledati $v$ prihodnost brez vpletanja željenih oziroma cilnjih stanj. Gre za simulacijo razvojnih trendov ob predpostavki, da vanje ne posegamo. Valorizacijski modeli so tisti, pri katerih sedanje ali prihodnje razmere $\mathrm{v}$ okolju presojamo $\mathrm{v}$ luči določenih ciljev, željenih stanj okolja. Vrednost je namreč vselej ocena, v koliki meri se stavrnost, sedanja ali prihodnja, sklada $z$ našimi željami, potrebami in interesi, skratka cilji. Vrednost je torej razlika med dejanskim stanjem in prepodstavljenim, željenim stanjem okolja. V resnici so šele valorizacijski modeli pravi načrtovalni modeli. Ti modeli imajo večinoma obliko analize zaradi že pokazane težke delitve med simulacijo sprememb, sprememb stvarnega prostora in njihovim vrednostnim opredeljevanjem. Poustvarjanje spememb je $v$ načelu analitični postopek. Velikokrat zato govorimo o vrednostni analizi prostora. Taka analiza seveda vodi $\mathrm{v}$ razgradnjo celote, kakršno predstavlja stvarnost, vodi $\mathrm{v}$ ločen, členjen poged na posamezne vidike željene stavrnosti. Načrtovanje je priprava na poseg v stvarnost, zato mora biti celovita, mora hkrati združiti vse sestavine stvarnosti. Ker je tudi načrt model, je, po definiciji, le približek, torej model stvarnosti. Načrtovanje je prav zato vselej nepopolno. Je pa značilnost sinteznih modelovta, da po definiciji ustvarjajo alternative, kar zahteva naslednjo raven modelov, to je odločitvene modele. Njihov temeljni 
namen je pripraviti odločitev glede izbora možne načrtovalne rešitve, različice načrta. Zaradi nepopolnosti načrtovanja je $\mathbf{k}$ tem modelom mogoče dodati še nadzorne modele, modele opazovanja, kar je pravzaprav tudi problem, ki ga je mogoče uvrstitvi v okviru GIS programov. Gre namreč za možnost uporabe različnih informacijskih virov daljinskega zaznavanja in skozi njihovo procesiranje $v$ okviru GIS okolja preverjati spremembe, ki so bodisi skladne $\mathrm{z}$ zastavljenim načrtom, bodisi od njega odstopajo.

\section{LITERATURA IN VIRI}

Banovec, T., 1972: Konstrukcija digitalnog modela reliefa za teritorij SR Slovenije, Automatizacija u geodeziji, Savet geodetskih inženjera $i$ geometra SFR Jugoslavije, Vrnjačka Banja, 23-24 nov. 1972, str. 304-312.

Kristan, B., 1972: SYMAP GZ - Automatizirani kartografski postupak za izradu tematskih karata, Automatizacija u geodeziji, Savet geodetskih inženjera i geometra SFR Jugoslavije, Vrnjačka Banja, 23-24 nov. 1972, str. 304-312.

Lyle, J.T., 1985: Design for Human Ecosystems, Van Nostrand, New York, str.277.

Marušič, J., 1981: Priročnik za uporabo programa GRID, Katedra za krajinsko arhitekturo, Biotehniška fakulteta, Ljubljana, str. 36.

Marušič, J., 1982: Programi za računalniško obdelavo prostorskih podatkov, Priročnik, Katedra za krajinsko arhitekturo, Biotehniška fakulteta, Ljubljana, str. 21.

Marušič, J., 1985: Prostor - Paket programov za krajinsko-prostorsko planiranje, Priročnik I-splošni del, str. 86, Priročnik II - ukazi, str. 83, Biotehniška fakulteta, Ljubljana.

Ogrin, D. et al., 1974: Analiza in valorizacija načrtovanih tras avto ceste na območju Ljubljana-Kranj, študija, Biotehniška fakulteta, Ljubljana, str. 121

Ogrin, D. et al., 1975: Metodologija krajinskega planiranja na primeru Goriških Brd, raziskovalna naloga, Biotehniška fakulteta, Ljubljana, 154.

Ogrin, D. et al., 1976: Jadran III: Projekt varstva človekovega okolja v Jadranski regiji Jugoslavije, sektor SR SLovenije, projekt - poročilo, Biotehniška fakulteta, Ljubljana, str. 54.

Vizovišek, M., 1990: Opredeljevanje vidnosti krajinskih prizorišč v postopku vrednotenja prostora, Diplomska naloga, mentor: J. Marušič, Študij krajinske arhitekture, Biotehniška fakulteta, Ljubljana.

\section{Opombe}

1 Primer je vzet iz diplomske naloge Vizovišek, M. 1990

$2 \mathrm{~J}$. Lyle to vednost označuje kot "immaterial presence" - "nematerialno prisotnost", zato da pokaže na njegovo drugačno naravo in ga loči od $z$ inventarizacijo zbranih podatkov - materialne prisotnosti, to je dejstev o konkretnem prostoru, ki ga načrtovalec obdeluje (Lyle, 1985, str. 158).

3 "rational problem-solving paradigm" - Glej Lyle, 1985, str. 131 
Priloga 1: Planski proces.

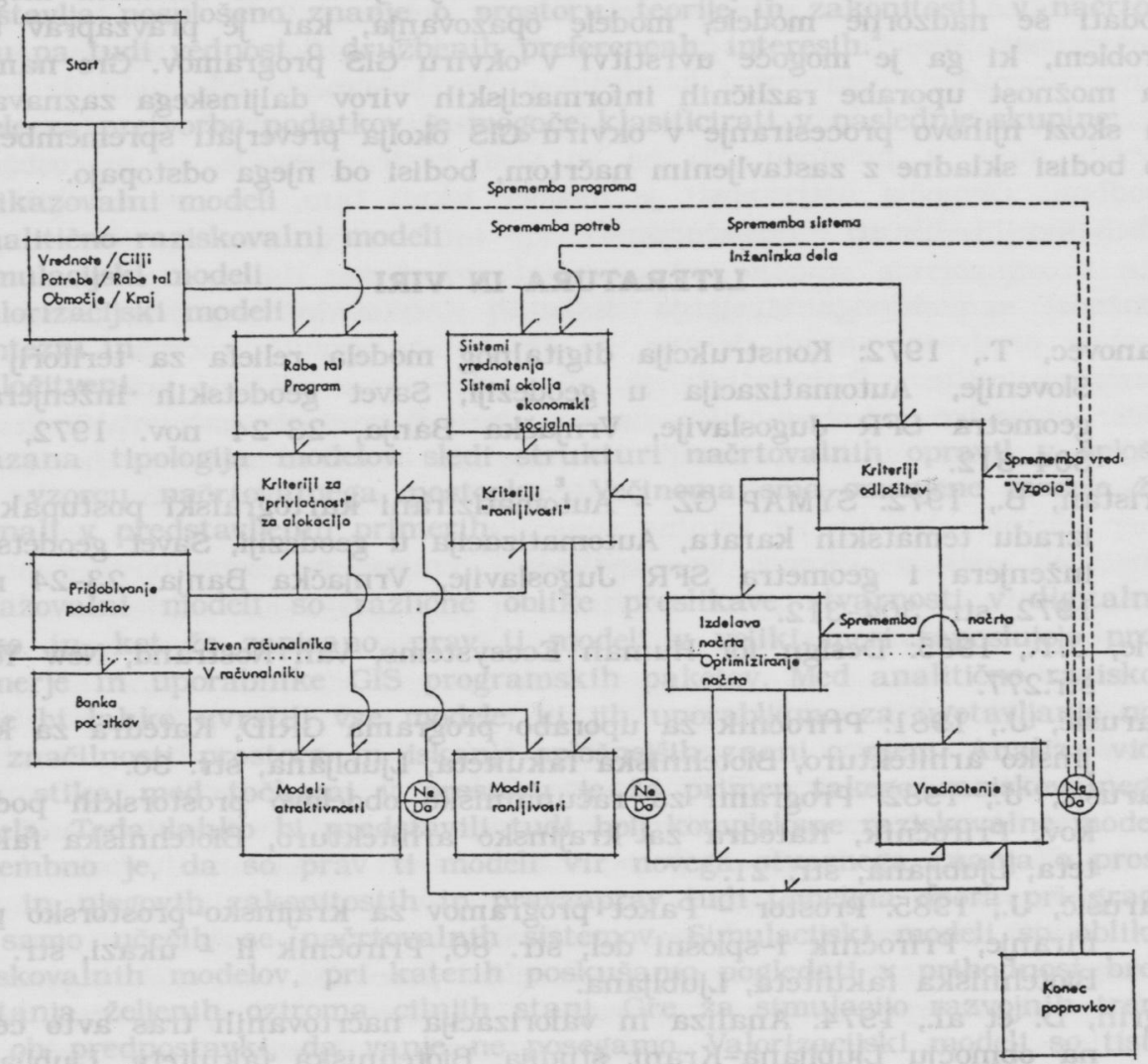


Priloga 2: Izdelava krajinskega načrta - delouni postopek.

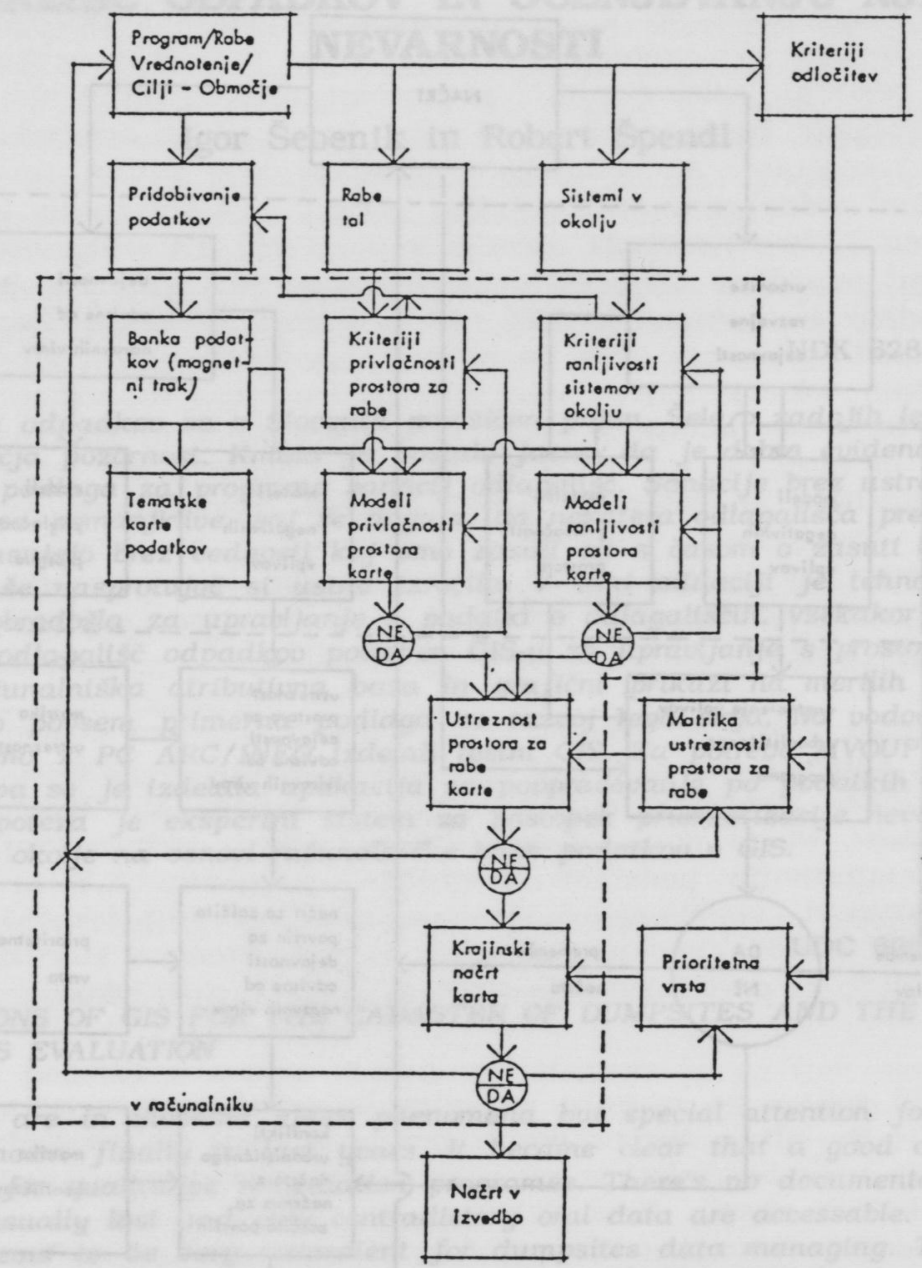


Priloga 3: Načrtovalski postopek - Jadran III.

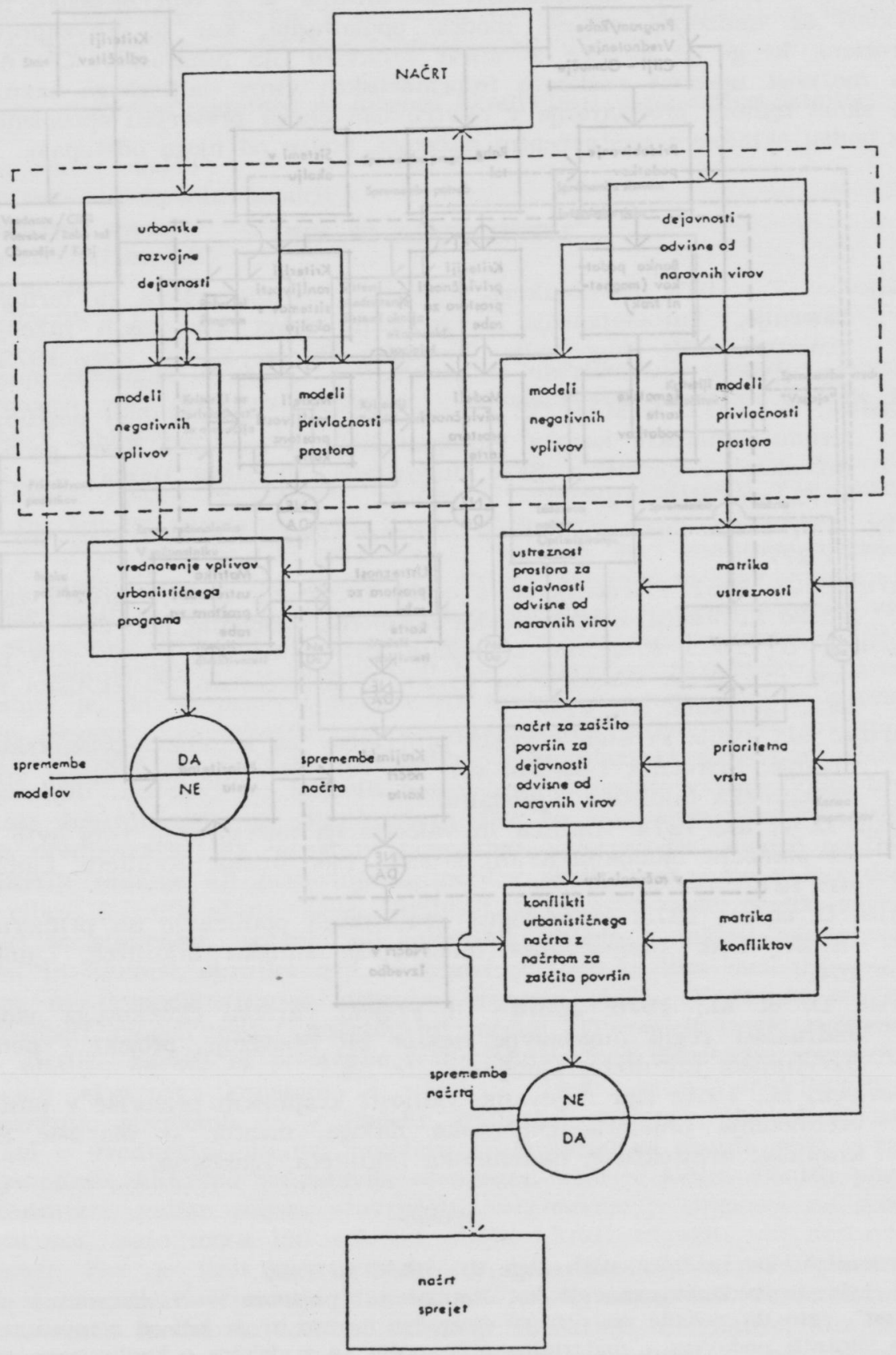

